\title{
PROPAGAÇÃO VEGETATIVA DE Piper amalago L. (PIPERACEAE) EM FUNÇÃO DE TIPOS DE ESTACA E SUBSTRATOS
}

\author{
Erik Nunes Gomes ${ }^{1}$, Diones Krinski ${ }^{2}$ \\ ${ }^{1}$ Mestrando em Agronomia - Produção Vegetal pela Universidade Federal do Paraná, Curitiba - PR. E-mail: \\ erikgomes93@hotmail.com \\ ${ }^{2}$ Professor Adjunto do Departamento de Ciências Biológicas da Universidade do Estado de Mato Grosso, \\ Campus Universitário de Tangará da Serra - MT. E-mail: dioneskrinski@gmail.com
}

RESUMO: Piper amalago L. é uma espécie perene pertencente à família Piperaceae com comprovada atividade leshmanicida, anti-inflamatória, ansiogênica, antimicrobiana, diurética e natriurética. $\mathrm{O}$ objetivo do presente trabalho foi avaliar o potencial de enraizamento de estacas caulinares das porções apicais, medianas e basais de Piper amalago L. em diferentes substratos. As diferentes estacas foram confeccionadas a partir de plantas coletadas em uma população natural, e plantadas em tubetes contendo os três substratos avaliados: solo agrícola peneirado, substrato comercial Plantmax ${ }^{\circledR}$ e vermiculita. O delineamento experimental foi o inteiramente casualizado em arranjo fatorial $3 \times 3$ (3 porções do ramo e 3 substratos), com 4 repetições de 12 estacas por unidade amostral. A avaliação ocorreu 45 dias após o plantio. As porcentagens de enraizamento variaram de 2,08 a $22,92 \%$. Não houve interação significativa entre os fatores. Avaliando os fatores isoladamente, constatou-se que o tipo de estaca apresentou significância apenas para a porcentagem de estacas com brotações. Estacas basais foram superiores às apicais para esta variável. O fator substrato foi significativo para todas as variáveis analisadas, exceto para a porcentagem de estacas com retenção das folhas. Maiores porcentagens de enraizamento foram verificadas utilizando o solo agrícola como substrato, atingindo 17,4\% em média. O solo foi também superior aos demais substratos no número, comprimento e massa fresca de raízes.

Palavras-chave: Jaborandi-falso. Estaquia. Enraizamento. Domesticação. Produção de mudas.

\section{VEGETATIVE PROPAGATION OF Piper amalago L. (PIPERACEAE) AS A FUNCTION OF CUTTING TYPES AND SUBSTRATES}

\begin{abstract}
Piper amalago L. is a perennial species of the Piperaceae family, with proven leishmanicidal, anti-inflammatory, anxiogenic, antimicrobial, diuretic and natriuretic activity, however there are few studies on the agronomic practices for this species. The aim of this study was to evaluate the rooting potential of apical, median and basal stem cuttings of Piper amalago L. on different substrates. Cuttings were made from plants collected in natural populations, and planted in plastic tubes containing the three evaluated substrates: sifted agricultural soil, commercial substrate Plantmax ${ }^{\circledR}$, and vermiculite. The experimental design was completely randomized in a factorial arrangement $3 \times 3$ ( 3 portions of the branch
\end{abstract}

Cultura Agronômica, Ilha Solteira, v.25, n.2, p.199-210, 2016 
and 3 substrates) with 4 replications and 12 cuttings as a sample unit. The evaluation occurred 45 days after planting. Rooting percentages ranged from 2.08 to $22.92 \%$. There was no significant interaction between the factors. Considering each factor singly, it was found that the cutting types showed significance only for the percentage of sprouted cuttings. Basal cuttings were superior than the apical ones to this variable. The substrate factor was significant for all variables, except for the percentage of cuttings with leaf retention. Higher rooting percentages were found when the agricultural soil was the substrate used, reaching on average $17.4 \%$. Soil was also superior to other substrates in the number, length and fresh weight of roots.

Key words: Jaborandi-falso. Cuttings. Rooting. Domestication. Seedling production.

\section{INTRODUÇÃO}

Piper amalago L., popularmente conhecida como jaborandi-falso ou pimenta-dajamaica, é uma planta perene que pode atingir de dois a sete metros de altura, possuindo folhas brilhosas e nervuras paralelas (MOREIRA, 2015; GUIMARÃES; VALENTE, 2001). A espécie vem sendo utilizada na medicina popular para aliviar dores no peito e estômago, com relatos de atividades anti-inflamatórias, analgésicas, anti-térmicas e vermífugas (NOVAES et al., 2014; PARMAR et al., 1997).

A composição química das raízes desta espécie revelou a presença, principalmente, de sesquiterpenos, pirrolidinas e isobutilamidas com efeitos antileishmanicida (CARRARA et al., 2013). Outros estudos farmacológicos com extratos de diferentes órgãos da planta demonstraram efeitos anti-inflamatórios (SOSA et al., 2002), antimicrobianos GUIMARÃES; VALENTE, 2001) ansiogênicos (LOPES et al., 2012), diuréticos e natriuréticos (NOVAES et al., 2014).

Apesar da relativa abundância de trabalhos avaliando atividades biológicas, não são encontrados na literatura relatos de práticas agronômicas para a espécie. O desenvolvimento de métodos de propagação adequados é fundamental por se tratar de uma das etapas inicias no processo de domesticação e cultivo. Considerando a seleção e posterior reprodução de genótipos superiores, especial atenção deve ser dada à propagação assexuada, uma vez que não apresenta variabilidade genética. Dentre os métodos de propagação assexuada, a estaquia é uma das técnicas de maior viabilidade econômica para o estabelecimento de plantios clonais, por permitir, a um custo relativamente menor, a multiplicação de genótipos selecionados em curto período de tempo (PAIVA; GOMES, 1993).

Diante do exposto, o objetivo do presente trabalho foi avaliar o potencial de enraizamento de estacas caulinares apicais, medianas e basais de Piper amalago L. em diferentes substratos, visando à produção de mudas da espécie.

\section{MATERIAL E MÉTODOS}

O material vegetal utilizado para a confecção das estacas foi coletado a partir de dez

Cultura Agronômica, Ilha Solteira, v.25, n.2, p.199-210, 2016 
indivíduos em uma população natural em local parcialmente sombreado no município de Adrianópolis/PR (24³6'11.9"S 4858'20.2"W - altitude $150 \mathrm{~m}$ ). A coleta foi realizada em dezembro de 2015, no final da tarde. O material vegetal foi umedecido e acondicionado em sacos de polietileno pretos para o transporte até casa de vegetação, onde foi mantido em nebulização intermitente por um período de 12 horas até a confecção das estacas.

O experimento foi conduzido no Departamento de Fitotecnia e Fitossanitarismo do Setor de Ciências Agrárias da Universidade Federal do Paraná, situado a $25^{\circ} 25^{\prime} 40^{\prime \prime} \mathrm{S}$ e 49¹6'23" O, a uma altitude de 934 m, na cidade de Curitiba/PR. O clima da região, segundo classificação de Köppen, é Cfb temperado úmido com verão ameno, inverno frio e seco, chuvas uniformemente distribuídas durante o ano e ocorrência de geadas severas frequentes.

As estacas foram confeccionadas com comprimento entre 10 e $12 \mathrm{~cm}$ com corte em bisel na base e reto no ápice. Realizou-se a estratificação dos ramos secundários em três partes, resultando nos três tipos de estacas avaliados: apicais, medianas e basais. Foi mantida uma folha reduzida a um terço do tamanho na região do ápice da estaca. Após a confecção, os propágulos foram submetidos à lavagem em água corrente por cinco minutos.

As estacas foram plantadas em tubetes plásticos de $120 \mathrm{~cm}^{3}$ de volume, preenchidos com os três diferentes substratos: substrato comercial Plantmax ${ }^{\circledR}$, solo agrícola peneirado (Tabela 1) e vermiculita de granulometria fina. Os tubetes foram dispostos de forma alternada em suportes plásticos com capacidade para 96 tubetes. As estacas foram mantidas em casa de vegetação com nebulização intermitente de 5 segundos a cada 30 minutos.

Tabela 1. Dados do laudo de análise do solo agrícola utilizado no presente experimento. Curitiba/PR, 2016.

\begin{tabular}{|c|c|c|c|c|c|c|c|c|c|c|c|}
\hline pI & & $\mathrm{Al}^{+3}$ & $\mathrm{H}^{+}+\mathrm{Al}^{+3}$ & $\mathrm{Ca}^{+2}$ & $\mathrm{Mg}^{+2}$ & $\mathbf{K}^{+}$ & SB & $\mathbf{P}$ & $\mathbf{S}$ & $\mathbf{C}$ & $\mathbf{V}$ \\
\hline $\mathrm{CaCl}_{2}$ & SMP & \multicolumn{6}{|c|}{$\mathrm{cmol} / \mathrm{dm}^{3}$} & \multicolumn{2}{|c|}{$\mathrm{mg} / \mathrm{dm}^{3}$} & $\mathrm{~g} / \mathrm{dm}^{3}$ & $\%$ \\
\hline 4,70 & 5,3 & 1,9 & 8,40 & 2,60 & 1,5 & 0,1 & 4,2 & 3,2 & - & 16,7 & 33 \\
\hline
\end{tabular}

O delineamento experimental utilizado foi inteiramente casualizado em arranjo fatorial 3x3 (três porções do ramo e três substratos), com quatro repetições e 12 estacas como unidade amostral, compreendendo 48 estacas por tratamento, com um total de 432 estacas no experimento.

Aos 45 dias após a instalação dos experimentos foi realizada a avaliação da porcentagem de estacas enraizadas, mortas, com retenção de folha e com brotações. Foram avaliados também o número médio de raízes, comprimento das três maiores raízes, massa fresca de raízes e massa fresca de brotações. Os dados foram transformados para $\log \mathrm{X}+10 \mathrm{e}$ então submetidos à análise de homogeneidade de variâncias pelo Teste de Bartlett. Após verificação da homogeneidade, as médias foram comparadas pelo Teste de Tukey a 5\% de probabilidade, utilizando o programa Assistat (SILVA; AZEVEDO, 2016).

\section{RESULTADOS E DISCUSSÃO}

A análise de variância revelou não haver significância na interação entre os fatores (Tabela 2). Avaliando os tratamentos isoladamente, constata-se que o tipo de estaca Cultura Agronômica, Ilha Solteira, v.25, n.2, p.199-210, 2016 
apresentou significância apenas para a porcentagem de estacas que emitiram brotações. $\mathrm{O}$ tipo de substrato foi o fator que exerceu maior influência, sendo significativo para todas as variáveis analisadas, exceto para a porcentagem de estacas que apresentaram retenção das folhas mantidas no momento da confecção (Tabela 2).

Tabela 2. Análise de variância para porcentagens de enraizamento (ENR), mortalidade (MOR), retenção das folhas (REF), brotações (BROT), número de raízes (NUR), comprimento das três maiores raízes (COMP), massa fresca das raízes (MFR) e massa fresca de brotações (MFB) em estacas apicais, medianas e basais de Piper amalago propagadas em três substratos: solo, Plantmax ${ }^{\circledR}$, e vermiculita. Curitiba/PR, 2016.

\begin{tabular}{|c|c|c|c|c|c|c|c|c|c|}
\hline \multirow{2}{*}{$\begin{array}{l}\text { Fonte de } \\
\text { variação }\end{array}$} & \multirow{2}{*}{ G.L. } & \multicolumn{8}{|c|}{ Valores de F } \\
\hline & & ENR & MOR & REF & BROT & NUR & COMP & MFR & MFB \\
\hline Substratos & 2 & $7,88^{* * *}$ & $4,80 *$ & $0,05^{\mathrm{ns}}$ & $5,83 * *$ & $8,29 * *$ & $8,07 * *$ & $5,36^{*}$ & $7,28 * *$ \\
\hline Estacas & 2 & $0,55^{\mathrm{ns}}$ & $1,50^{\mathrm{ns}}$ & $0,09^{\mathrm{ns}}$ & $5,57 * *$ & $0,85^{\mathrm{ns}}$ & $0,51^{\mathrm{ns}}$ & $1,56^{\mathrm{ns}}$ & $1,28^{\mathrm{ns}}$ \\
\hline Interação & 4 & $0,53^{\mathrm{ns}}$ & $1,47^{\mathrm{ns}}$ & $0,34^{\mathrm{ns}}$ & $0,78^{\mathrm{ns}}$ & $0,74^{\mathrm{ns}}$ & $0,28^{\mathrm{ns}}$ & $0,81^{\mathrm{ns}}$ & $0,69^{\text {ns }}$ \\
\hline Tratamentos & 8 & $2,37 *$ & $2,31 *$ & $0,20^{\mathrm{ns}}$ & $3,24 *$ & $2,66^{*}$ & $2,29 *$ & $2,13^{\mathrm{ns}}$ & $2,49 *$ \\
\hline Resíduo & 27 & - & - & - & - & - & - & - & - \\
\hline C.V. (\%) & & 15,96 & 2,18 & 16,26 & 15,35 & 6,20 & 2,87 & 0,08 & 0,14 \\
\hline
\end{tabular}

*significativo a 5\%; **significativo a 1\%; NS: não significativo. Obs.: A análise foi feita sobre dados transformados em $\log X+10$.

Os valores de porcentagens de enraizamento encontrados para P. amalago no presente trabalho variaram de 2,08\%, para estacas basais em Plantmax ${ }^{\circledR}$, a 22,92\% para estacas basais em solo agrícola. Estes valores podem ser considerados baixos se comparados a outras espécies do gênero Piper (Tabela 3). Cunha et al. (2015) obtiveram valores superiores a $85 \%$ em estaquia caulinar de Piper hispidum Sw.. Pescador et al. (2007) relataram valores superiores à $60 \%$ para estacas medianas de Piper mikanianum (Kunth) Steudel. Para estacas caulinares medianas de Piper umbellatum L., Mattana et al. (2009) relataram valores de até $37,5 \%$.

Todavia, são comuns as diferenças no enraizamento de espécies do mesmo gênero, podendo estas diferenças estarem relacionadas aos diferentes potenciais genéticos para emissão de raízes adventícias e também à presença ou não de auxinas e co-fatores endógenos e possíveis barreiras anatômicas de cada espécie. Bona et al. (2005) avaliaram o potencial de enraizamento de estacas de três espécies do gênero Baccharis (Asteraceae). A espécie Baccharis trimera (Less.) DC. apresentou resultados de até 96,6\% de estacas enraizadas, enquanto que em Baccharis articulata (Lam.) Pers. e Baccharis stenocephala Baker os maiores valores foram de $38,4 \%$ e $23,3 \%$, respectivamente. Em estudo com diferentes espécies de Passiflora spp. (maracujá), também foram verificadas diferenças entre os materiais vegetais. Passiflora gibertii N. E. Br. apresentou média de porcentagem de enraizamento de 33,57\% superior às espécies Passiflora nitida Kunth., Passiflora edulis Sims e Passiflora setacea DC. (RONCATTO et al., 2008).

No presente trabalho, o desempenho observado para estacas de $P$. amalago pode estar associado a barreiras anatômicas para a emissão de raízes, uma vez que na descrição anatômica do caule da espécie, Santos et al. (2015) relatam que os feixes vasculares estão 
dispostos em dois círculos dentro do cilindro vascular, e que o círculo mais externo mostra vários feixes vasculares e a presença de calotas de fibras perivasculares adjacentes do floema. Em estacas de caramboleira (Averrhoa carambola L.) foi relatado que a presença de fibras do floema primário com células de paredes mais espessadas, situadas logo abaixo do parênquima cortical pode dificultar a passagem dos primórdios radiculares (BASTOS, 2006). A presença de um anel contínuo de colênquima angular no córtex, relatado por Santos et al. (2015), em P. amalago, também pode vir a se tornar uma barreira anatômica se sofrer lignificação, processo comum no gênero Piper, como já relatado por Albiero et al. (2005) em P. crassinervium e por Nascimento e Vilhena-Potiguara (1999) em Piper hispidinervium C. DC.

Outra explicação para a menor porcentagem de enraizamento em relação ao encontrado na literatura é a ocorrência de abscisão na região do nó. Dousseau (2009) relatou a presença de abscisão na região do nó em estacas de Piper aduncum L., cerca de cinco dias após o plantio, segundo a autora, todavia, este processo não interferiu na formação de raízes adventícias, diferentemente do observado no presente trabalho.

Para as estacas de $P$. amalago foi observado que nenhuma estaca que sofreu abscisão apresentou formação de raízes adventícias. Este fato se deve, possivelmente ao fato da abscisão separar da base da estaca, parte do caule juntamente com a folha mantida na ocasião da confecção. De fato, podem ser observadas baixas porcentagens de estacas com retenção de folhas (Tabela 3), o que pode ser prejudicial ao enraizamento, uma vez que a presença das folhas nas estacas constitui fonte de auxinas e outros cofatores necessários para o enraizamento (HARTMANN et al., 2011). Não obstante, maiores porcentagens de enraizamento foram verificadas utilizando o solo agrícola como substrato, atingindo $17,36 \%$ na média dos três tipos de estaca (Tabela 3).

Estes resultados diferem do relatado por Cunha et al. (2015) que encontraram maiores porcentagens de enraizamento de estacas de $P$. hispidum quando utilizaram areia como substrato. Estes autores atribuíram os resultados ao fato de a espécie ser mais exigente em aeração do que ao umedecimento no substrato, uma vez que a areia possui maior quantidade de macroporos que facilitam na aeração, diminuindo a mortalidade das estacas e facilitando o enraizamento. Mattana et al. (2009), relatam que substratos puros, solo e areia, não favoreceram o desenvolvimento de brotações e raízes vigorosas, por serem pobres em nutrientes, refletindo em menores massas frescas de brotações e de raízes. Biasi e Costa (2003), de maneira semelhante, relataram menores valores de massa fresca de raízes no substrato solo em ralação a casca de arroz, para estacas de Lippia alba (Mill.) N. E. Brown. Os autores de ambos os trabalhos não recomendam a utilização de solo para a produção de mudas por estaquia.

Cultura Agronômica, Ilha Solteira, v.25, n.2, p.199-210, 2016 
Tabela 3. Porcentagens médias de enraizamento, mortalidade, retenção de folhas e emissão de brotações em estacas caulinares apicais, medianas e basais de Piper amalago em diferentes substratos (substrato comercial Plantmax ${ }^{\circledR}$, solo agrícola peneirado e vermiculita de granulometria fina). Curitiba/PR, 2016.

\begin{tabular}{|c|c|c|c|c|}
\hline \multirow{3}{*}{ Substratos } & \multicolumn{3}{|c|}{ Enraizamento (\%) } & \multirow{3}{*}{ Média } \\
\hline & \multicolumn{3}{|c|}{ Tipo de Estacas } & \\
\hline & Apical & Mediana & Basal & \\
\hline Solo & $10,42 \mathrm{aA}$ & $18,75 \mathrm{aA}$ & $22,92 \mathrm{aA}$ & $17,36 \mathrm{a}$ \\
\hline Plantmax $^{\circledR}$ & $4,17 \mathrm{aA}$ & $4,17 \mathrm{aA}$ & $2,08 \mathrm{bA}$ & $3,47 \mathrm{~b}$ \\
\hline Vermiculita & $4,17 \mathrm{aA}$ & $6,25 \mathrm{aA}$ & $8,33 \mathrm{abA}$ & $6,25 \mathrm{~b}$ \\
\hline Média & $6,25 \mathrm{~A}$ & $9,72 \mathrm{~A}$ & $11,11 \mathrm{~A}$ & \\
\hline \multicolumn{5}{|c|}{ Mortalidade (\%) } \\
\hline & \multicolumn{3}{|c|}{ Tipo de Estacas } & \\
\hline Substratos & Apical & Mediana & Basal & Média \\
\hline Solo & $89,58 \mathrm{aA}$ & $79,17 \mathrm{bA}$ & $75,00 \mathrm{bA}$ & $81,25 \mathrm{~b}$ \\
\hline Plantmax $^{\circledR}$ & $89,58 \mathrm{aA}$ & $95,83 \mathrm{aA}$ & $93,75 \mathrm{aA}$ & $93,06 \mathrm{a}$ \\
\hline Vermiculita & $93,75 \mathrm{aA}$ & $83,33 \mathrm{abA}$ & $85,42 \mathrm{abA}$ & $87,50 \mathrm{ab}$ \\
\hline Média & $90,97 \mathrm{~A}$ & $86,11 \mathrm{~A}$ & $84,72 \mathrm{~A}$ & \\
\hline \multicolumn{5}{|c|}{ Retenção de folhas (\%) } \\
\hline & \multicolumn{3}{|c|}{ Tipo de Estacas } & \\
\hline Substratos & Apical & Mediana & Basal & Média \\
\hline Solo & $4,17 \mathrm{aA}$ & $4,17 \mathrm{aA}$ & $6,25 \mathrm{aA}$ & $4,86 \mathrm{a}$ \\
\hline Plantmax $^{\circledR}$ & 8,33 aA & $4,17 \mathrm{aA}$ & $2,08 \mathrm{aA}$ & $4,86 \mathrm{a}$ \\
\hline Vermiculita & $4,17 \mathrm{aA}$ & $4,17 \mathrm{aA}$ & $4,17 \mathrm{aA}$ & $4,17 \mathrm{a}$ \\
\hline Média & $5,56 \mathrm{~A}$ & $4,17 \mathrm{~A}$ & $4,17 \mathrm{~A}$ & \\
\hline \multicolumn{5}{|c|}{ Emissão de brotações (\%) } \\
\hline & \multicolumn{3}{|c|}{ Tipo de Estacas } & \\
\hline Substratos & Apical & Mediana & Basal & Média \\
\hline Solo & $4,17 \mathrm{aB}$ & $22,92 \mathrm{aAB}$ & $25,00 \mathrm{aA}$ & $17,36 \mathrm{a}$ \\
\hline Plantmax $^{\circledR}$ & $2,08 \mathrm{aA}$ & $4,17 \mathrm{bA}$ & $6,25 \mathrm{bA}$ & $4,17 \mathrm{~b}$ \\
\hline Vermiculita & $2,08 \mathrm{aA}$ & $10,42 \mathrm{abA}$ & $10,42 \mathrm{abA}$ & $7,64 \mathrm{ab}$ \\
\hline Média & $2,78 \mathrm{~B}$ & $12,50 \mathrm{AB}$ & $13,89 \mathrm{~A}$ & \\
\hline
\end{tabular}

*Médias seguidas pela mesma letra maiúscula nas linhas e minúscula nas colunas não diferem entre si pelo teste de Tukey a $5 \%$ de probabilidade.

De fato, é comum encontrar relatos na literatura de que o solo como substrato único possua alta densidade e pouca porosidade (KÄMPF, 2000), o que, via de regra, prejudica o desenvolvimento das raízes. Para $P$. amalago, no entanto, o solo se apresentou como o mais adequado tanto para o enraizamento quanto para as características de número de raízes, comprimento médio de raízes, e massa fresca de raízes (Tabela 4). Este fato pode ser explicado pelo fato de que, dentre os substratos avaliados, o solo agrícola é o que possui maior disponibilidade de nutrientes e capacidade de retenção de água, sem apresentar características físicas que prejudiquem o enraizamento da espécie.

Cultura Agronômica, Ilha Solteira, v.25, n.2, p.199-210, 2016 
A emissão de brotações é uma característica importante para a formação de mudas de qualidade, uma vez que, após o esgotamento das reservas da estaca, a presença de novas folhas é fundamental para a nutrição da planta. Observou-se no presente trabalho maior porcentagem de estacas basais com brotações quando comparadas com apicais (Tabela 3), este fato pode ser observado pelo fato de estacas basais apresentaram maior maturidade dos tecidos, o que proporciona maior capacidade de disponibilizar os carboidratos necessários ao crescimento das raízes e de brotações (SOUSA et al., 2013).

Tabela 4. Médias e desvio padrão de número de raízes, comprimento das três maiores raízes, massa da matéria fresca de raízes e de brotações de estacas caulinares apicais, medianas e basais de Piper aduncum em diferentes substratos (substrato comercial Plantmax $^{\circledR}$, solo agrícola peneirado e vermiculita de granulometria fina). Curitiba/PR, 2016.

\begin{tabular}{|c|c|c|c|c|}
\hline \multicolumn{5}{|c|}{ Número de raízes por estaca } \\
\hline \multirow[b]{2}{*}{ Substratos } & \multicolumn{3}{|c|}{ Tipo de Estacas } & \multirow[b]{2}{*}{ Média } \\
\hline & Apical & Mediana & Basal & \\
\hline Solo & $5,50 \mathrm{aA}$ & $2,81 \mathrm{aA}$ & $3,42 \mathrm{aA}$ & $3,91 \mathrm{a}$ \\
\hline Plantmax ${ }^{\circledR}$ & $1,25 \mathrm{bA}$ & $0,50 \mathrm{aA}$ & $1,25 \mathrm{aA}$ & $1,00 \mathrm{~b}$ \\
\hline Vermiculita & $0,87 \mathrm{bA}$ & $1,13 \mathrm{aA}$ & $2,13 \mathrm{aA}$ & $1,38 \mathrm{~b}$ \\
\hline Média & $2,54 \mathrm{~A}$ & $1,48 \mathrm{~A}$ & $2,26 \mathrm{~A}$ & \\
\hline \multicolumn{5}{|c|}{ Comprimento médio das raízes $(\mathrm{cm})$} \\
\hline & \multicolumn{3}{|c|}{ Tipo de Estacas } & \\
\hline Substratos & Apical & Mediana & Basal & Média \\
\hline Solo & $1,86 \mathrm{aA}$ & $1,12 \mathrm{aA}$ & $1,54 \mathrm{aA}$ & $1,51 \mathrm{a}$ \\
\hline Plantmax $^{\circledR}$ & $0,51 \mathrm{bA}$ & $0,31 \mathrm{aA}$ & $0,46 \mathrm{aA}$ & $0,43 \mathrm{~b}$ \\
\hline Vermiculita & $0,38 \mathrm{abA}$ & $0,42 \mathrm{aA}$ & $0,59 \mathrm{aA}$ & $0,47 \mathrm{~b}$ \\
\hline Média & $0,92 \mathrm{~A}$ & $0,62 \mathrm{~A}$ & $0,87 \mathrm{~A}$ & \\
\hline \multicolumn{5}{|c|}{ Massa da matéria fresca de raízes (g) } \\
\hline & \multicolumn{3}{|c|}{ Tipo de Estacas } & \\
\hline Substratos & Apical & Mediana & Basal & Média \\
\hline Solo & $0,043 \mathrm{aA}$ & $0,013 \mathrm{aA}$ & $0,028 \mathrm{aA}$ & $0,028 \mathrm{a}$ \\
\hline Plantmax $^{\circledR}$ & $0,008 \mathrm{bA}$ & $0,003 \mathrm{aA}$ & $0,014 \mathrm{aA}$ & $0,008 \mathrm{~b}$ \\
\hline Vermiculita & $0,006 \mathrm{bA}$ & $0,004 \mathrm{aA}$ & $0,009 \mathrm{aA}$ & $0,006 \mathrm{~b}$ \\
\hline Média & $0,019 \mathrm{~A}$ & $0,007 \mathrm{~A}$ & $0,017 \mathrm{~A}$ & \\
\hline \multicolumn{5}{|c|}{ Massa da matéria fresca de brotações (g) } \\
\hline & \multicolumn{3}{|c|}{ Tipo de Estacas } & \\
\hline Substratos & Apical & Mediana & Basal & Média \\
\hline Solo & $0,048 \mathrm{aA}$ & $0,061 \mathrm{aA}$ & $0,069 \mathrm{aA}$ & $0,059 \mathrm{a}$ \\
\hline Plantmax $^{\circledR}$ & $0,002 \mathrm{aA}$ & $0,005 \mathrm{aA}$ & $0,026 \mathrm{aA}$ & $0,011 \mathrm{~b}$ \\
\hline Vermiculita & $0,005 \mathrm{aA}$ & $0,045 \mathrm{aA}$ & $0,016 \mathrm{aA}$ & $0,022 \mathrm{~b}$ \\
\hline Média & $0,019 \mathrm{~A}$ & $0,037 \mathrm{~A}$ & $0,37 \mathrm{~A}$ & \\
\hline
\end{tabular}

*Médias seguidas pela mesma letra maiúscula nas linhas e minúscula nas colunas não diferem entre si pelo teste de Tukey a $5 \%$ de probabilidade.

Cultura Agronômica, Ilha Solteira, v.25, n.2, p.199-210, 2016 
A presença de nutrientes é também fator importante para a emissão de brotações, explicando as maiores porcentagens médias observadas para as estacas de P. amalago quando utilizado o solo como substrato em relação ao substrato Plantmax ${ }^{\circledR}$. Por este mesmo motivo se explicam os maiores valores de massa fresca de brotações no substrato solo (Tabela 4). Gomes et al. (2016) observaram, de maneira semelhante, maior número de brotações em estacas de $P$. umbellatum em substrato Plantmax ${ }^{\circledR}$ em comparação com vermiculita, atribuindo a superioridade à maior disponibilidade de nutrientes no primeiro substrato.

Fator importante e comum para a indução de rizogênese adventícia em estacas caulinares é a aplicação de reguladores vegetais, especialmente auxinas. No presente trabalho, por se tratar de uma avaliação inicial, optou-se pela não utilização destes reguladores visando à avaliação do potencial intrínseco da espécie. Todavia, em vista aos baixos percentuais de enraizamento, a aplicação de reguladores pode ser uma alternativa viável. Apesar dos resultados terem demonstrado baixo potencial de rizogênese da espécie, ressalta-se que este é o primeiro relato de pesquisa com propagação vegetativa de $P$. amalago, e que são necessários estudos complementares envolvendo aspectos fisiológicos como o balanço hormonal das plantas afetado pela sazonalidade e aplicação de reguladores vegetais, visando maior viabilidade na propagação da espécie para fins de cultivo e conservação.

\section{CONCLUSÃO}

Não foram observadas diferenças entre a porção do ramo de onde são confeccionadas as estacas para o enraizamento de $P$. amalago. O solo agrícola se mostrou o substrato mais adequado para a rizogênese de estacas caulinares da espécie. São necessários estudos complementares envolvendo aspectos fisiológicos, especialmente relacionados à sazonalidade e aplicação de reguladores de crescimento, para definir protocolos adequados de propagação vegetativa de $P$. amalago.

\section{AGRADECIMENTOS}

Os autores agradecem à Coordenação de Aperfeiçoamento de Pessoal de Nível Superior, pelo apoio e bolsas concedidas, ao biólogo Bruno Felipe Camera pelo auxílio na coleta e confecção das estacas e ao professor Dr. Cícero Deschamps pela disponibilização do substrato comercial e solo agrícola utilizados no experimento.

\section{REFERÊNCIAS BIBLIOGRÁFICAS}

AlBIERO, A. L. M; PAOLI, A. A. S.; SOUZA, L. A.; MOURÃO, K. S. Morphology and anatomy of vegetative organs of Piper crassinervium H. B. \& K. (Piperaceae). Acta Botânica Brasílica, Belo Horizonte, v. 19, n. 1, p.305-312, 2005. 
BASTOS, D. C. Propagação da caramboleira por estacas caulinares e caracterização anatômica e histológica da formação de raízes adventícias. 2006. 65 f. Tese (Doutorado em Agronomia) - Escola Superior de Agricultura "Luiz de Queiroz", Universidade de São Paulo, Piracicaba, 2006.

BIASI, L. A.; COSTA, G. Propagação vegetativa de Lippia alba. Ciência Rural, Santa Maria, v. 33, n. 3, p.455-459, 2003. Disponível em: http://www.scielo.br/scielo.php?script=sci_arttext\&pid=S0103-84782003000300010.

Acesso em 27 Jul. 2016.

BONA, C. M.; BIASI, L. A.; ZANETTE, F.; NAKASHIMA, T. Estaquia de três espécies de Baccharis. Ciência Rural, Santa Maria, v. 35, n. 1, p.223-226, 2005. Disponível em: http://www.scielo.br/scielo.php?script=sci_arttext\&pid=S0103-

84782005000100037\&lng=en\&nrm=iso . Acesso em: 27 jul. 2016.

CARRARA, V. S.; CUNHA-JÚNIOR, E. F.; TORRES-SANTOS, E. C.; CORRÊA, A. G.; MONTEIRO, J. L.; DEMARCHI, I. G.; LONARDONI, M. V. C.; CORTEZ, D. A. G. Antileishmanial activity of amides from Piper amalago and synthetic analogs. Revista Brasileira de Farmacognosia, Curitiba, v. 23, n. 3, p.447-454, 2013. Disponível em: http://www.scielo.br/scielo.php?script=sci_arttext\&pid=S0102-

695X2013000300008\&lng=en\&nrm=iso . Acesso em: 23 jul. 2016.

CUNHA, A. L. B.; CHAVES, F. C. M.; BATISTA, A. C.; HIDAlGO, A. F. Propagação vegetativa de estacas de Piper hispidum $\mathrm{Sw}$. em diferentes substratos. Revista Brasileira de Plantas Medicinais, Botucatu, v. 17, n. 4, supl. 1, p.685-692, 2015. Disponível em: http://www.scielo.br/scielo.php?script=sci_arttext\&pid=S1516-

05722015000500685\&lng=en\&nrm=iso . Acesso em: 27 jul. 2016.

DOUSSEAU, S. Propagação, características fotossintéticas, estruturais, fitoquímicas e crescimento inicial de Piper aduncum L. (Piperaeae). 2009. 140 f. Dissertação (Mestrado em Agronomia) - Universidade Federal de Lavras, Lavras, 2009.

GOMES, E. N.; KRINSKI, D.; CAMERA, B. F.; DESCHAMPS, C. Enraizamento de estacas de Piper umbellatum (Piperaceae) em função do comprimento da estaca e substratos In: SIMPÓSIO INTERDISCIPLINAR DE PRÁTICAS DE PRODUÇÃO AGRÍCOLA E CONSERVAÇÃO AMBIENTAL, 1., 2016, Tangará da Serra. Anais... Tangará da Serra/MT: PPGASP, 2016. Disponível em: http://siec.unemat.br/anais/!default/impressaopdf.php? $\mathrm{r}=\mathrm{NTU} w \mathrm{Mg}==\& \mathrm{i}=\mathrm{MzAxMzI}=\& \mathrm{p}=0 \& \mathrm{y}=\mathrm{MA}==\& \mathrm{v}=\mathrm{MA}==\& \mathrm{~d}=\mathrm{SQ}==\& \mathrm{cache}=147$ 6494587 . Acesso em: 20 ago. 2016.

Guimarães, E. F.; VAlEnte, M. C. Piper L. In: REITZ, R. (ed.). Flora Ilustrada Catarinense - Piperaceae. Itajaí: Herbário Barbosa Rodrigues, 2001. cap. 1, p. 1-45.

HARTMANn, H. T.; KESTER, D. E.; DAVIES JUNIOR, F. T.; GENEVE, R. L. Plant propagation: principles and practices. 8. ed. New Jersey: Englewood Clipps, 2011. 900 p.

KÄMPF, A. N. Produção comercial de plantas ornamentais. Guaíba: Agropecuária, 2000. 254 p.

Cultura Agronômica, Ilha Solteira, v.25, n.2, p.199-210, 2016 
LOPES, J. J.; MARX, C.; INGRASSIA, R.; PICADA, J. N.; PEREIRA, P.; FERRAZ, A. D. B. F. Neurobehavioral and toxicological activities of two potentially CNS-acting medicinal plants of Piper genus. Experimental and Toxicologic Pathology, Jena, v. 64, n. 1, p.9-14, 2012.

MATTANA, R. S.; FRANCO, V. F.; YAMAKI, H. O.; MAIA E ALMEIDA, C. I.; MING, L. C. Propagação vegetativa de plantas de pariparoba [Pothomorphe umbellata (L.) Miq.] em diferentes substratos e número de nós das estacas. Revista Brasileira de Plantas Medicinais, Botucatu, v. 11, n. 3, p.325-329, 2009. Disponível em: http://www.scielo.br/scielo.php?script=sci_arttext\&pid=S1516-05722009000300015

Acesso em: 26 jul. 2016.

MOREIRA, F. M. F. Avaliação da atividade anti-Mycobacterium tuberculosis e Antiproliferativa: Piper amalago L. e derivados $\beta$-carbolínicos. 2015. 61 f. Dissertação (Mestrado em Ciências da Saúde) - Faculdade Ciências da Saúde Universidade Federal da Grande Dourados, Dourados, 2015.

NASCIMENTO, M. E.; VILHENA-POTIGUARA, V. C. R. Aspectos anatômicos dos órgãos vegetativos de Piper hispidinervium C. DC. (Piperaceae) e suas estruturas secretoras. Boletim do Museu do Pará Emílio Goeldi, Belém, v. 15, n. 1, p.39-104, 1999.

NOVAES, A. S.; MOTA, J. S.; BARISON, A.; VEBER, C. L.; NEGRÃO, F. J.; KASSUYA, C. A. L.; BARROS, M. E. B. Diuretic and antilithiasic activities of ethanolic extract from Piper amalago (Piperaceae). Phytomedicine, Amsterdam, v. 21, n. 4, p.523$528,2014$.

15;21(4):523-8

PAIVA H. N.; GOMES J. M. Propagação vegetativa de espécies florestais. Viçosa: Universidade Federal de Viçosa, 1993. 40 p.

PARMAR, V. S.; JAIN, S. C.; BISHT, K. S.; JAIN, R.; TANEJA, P.; JHA, A.; BOLL, P. M. Phytochemistry of the genus Piper. Phytochemistry, Washington, v. 46, n. 4, p.597673, 1997.

PESCADOR, R.; VOLTONI, A. C.; GIRARDI, C. G.; ROSA, F. A. F. Estaquia de pariparoba-do-Rio Grande do Sul sob efeito do ácido indol-butírico em dois substratos. Scientia Agraria, Curitiba, v. 8, n. 4, p.391-398, 2007.

RONCATTO, G.; NOGUEIRA FILHO, G. C.; RUGGIERO, C. O.; OLIVEIRA, J. C.; MARTINS, A. B. G. Enraizamento de estacas herbáceas de diferentes espécies de maracujazeiro. Revista Brasileira de Fruticultura, Jaboticabal, v. 30, n. 4, p.1094-1099, 2008. Disponível em: http://www.scielo.br/scielo.php?script=sci_arttext\&pid=S010029452008000400041 . Acesso em: 27 jul. 2016.

SANTOS, V. L. P.; FRANCO, C. R. C.; AMANO, E.; MESSIAS-REASON, I. J.; BUDEL J. M. Anatomical investigations of Piper amalago (jaborandi-manso) for the quality control. Revista Brasileira de Farmacognosia, Curitiba, v. 25, n. 2, p.85-91, 2015. Disponível em: 
http://www.scielo.br/scielo.php?script=sci_arttext\&pid=S0102-695X2015000200085 Acesso em: 26 jul. 2016.

SILVA, F. A. S.; AZEVEDO, C. A. V. Comparison of means of agricultural experimentation data through different tests using the software Assistat. African Journal of Agricultural Research, Lagos, v.37, n. 11, p.3527-3531, 2016. Disponível em: http://www.academicjournals.org/journal/AJAR/article-full-text-pdf/091D87F60502 Acesso em: 20 set. 2016.

SOSA, S.; BALICK, M. J.; ARVIGO, R.; ESPOSITO, R. G.; PIZZA, C.; ALTINIER, G.; TUBARO, A. Screening of the topical anti-inflammatory activity of some Central American plants. Journal of Ethnopharmacology, Shannon, v. 81, n. 2, p.211-215, 2002.

SOUSA, C. M.; BUSQUET, R. N.; VASCONCELlOS, M. A. S.; MIRANDA, R. M. Effects of auxin and misting on the rooting of herbaceous and hardwood cuttings from the fig tree. Revista Ciência Agronômica, Fortaleza, v. 44, n. 2, p.334-338, 2013. Disponível em: http://www.scielo.br/scielo.php?pid=S1806-66902013000200016\&script=sci_arttext . Acesso em: 20 set. 2016. 
